\title{
Influences of Virtual Spokespersons' Characteristics on Brand Personality
}

\author{
Bingyu $\mathrm{Hu}^{1, *}$ \\ ${ }^{1}$ School of Art, Soochow University, Suzhou, Jiangsu 215000, China \\ *Corresponding author. Email: 3028983173@qq.com
}

\begin{abstract}
In today's business competition, product bands have played a significant effect on consumers' purchasing behaviors, making brand image building a key component of business development strategy. As an essential aspect of brand image, the brand spokesperson is an important medium to deliver the brand personality and culture to consumers. To reveal the relationship between the characteristics of brand virtual spokespersons and the expression of brand personality, this paper conducts an empirical analysis by using "Likability, Expertise, Relevance" as the variables indicating the characteristics of brand virtual spokespersons, and using "Ren, Zhi, Yong, Ya, Le" as the ones indicating brand personality. Results show that the expertise of virtual spokespersons has a significant impact on the Le dimension of brand personality. In contrast, expertise has a significant positive correlation with the Ren, Zhi, Yong, Ya dimensions of brand personality, and a significant negative correlation with the Le dimension. However, the relevance of virtual spokespersons cannot express brand personality.
\end{abstract}

Keywords: virtual; spokesman; brand; personality; image

\section{INTRODUCTION}

Since the 21st century, the global market has gradually moved towards the era of brand economy. Aaker, a famous brand scholar, once pointed out that marketing in the $21 \mathrm{st}$ century is brand competition [1]. Nowadays, due to the numerous brands in various fields, there is fierce competition among brands. In order to enhance the competitiveness of brands, it has become a very important way for brands to use spokespersons to publicize their brands. According to one statistic, as of $2006,50 \%$ of the top 100 enterprises in the world have used virtual spokespersons or real spokespersons. Nowadays, we can find a spokesperson in almost every advertisement.

Brand spokespersons are mainly divided into two types: celebrity spokespersons and virtual spokespersons. The celebrity spokesman is a kind of spokesman image which is commonly used in various enterprises. Because stars have certain popularity and social influence, enterprises can quickly expand the popularity of brands and products with the help of these, so as to narrow the distance between brands and consumers, and win the trust of consumers[2]. enterprises often encounter some problems when they adopt celebrity spokespersons. First of all, celebrity spokespersons have a high cost of endorsement, sometimes gains cannot make up for losses. Secondly, although the products of enterprises are not directly related to stars, when stars appear in negative news, enterprises will also be negatively affected. Finally, in order to publicize the brand and expand its influence, enterprises often look for stars with relatively large reputation to endorse their products. However, enterprises often fail to take into account the coincidence and relevance between the personality and temperament of stars and the quality and connotation of products, resulting in the inadequate expression of the image and personality of the brand. Therefore, the advantages of customized virtual spokesperson strategies in terms of economic costs and brand promotion risks are gradually recognized by many enterprises [3]. Virtual spokesmen do not have the problem of celebrity spokesmen, and the continuous development of technology provides broad space for virtual spokesmen. CG technology, 3D production, motion capture, holographic technology, 3D printing, various new technologies emerge one after another, and virtual characters can participate in people's lives in more and more ways. Based on these technologies, the created virtual characters can also be endowed with various humanized functions such as language function, game function, music function and communication function. At the same time, according to the needs of planners can be arbitrary transformation until consumer satisfaction [4]. Its cost only involves design and manufacturing, and it can also adapt to various advertising designs and achieve many shooting effects that cannot be achieved by human beings. Its image has strong plasticity and uniqueness[5]. so nowadays, more and more brands begin to use virtual spokespersons.

However, even though many companies have put virtual spokespersons into use and the effect is very good, there are still many brands that do not pay enough attention to the importance of virtual spokespersons to the expression of brand personality. Therefore, the virtual spokespersons developed by many brands are not attractive enough, so they are quickly forgotten by people. In today's highly competitive market for virtual spokespersons, many brands 
try to highlight their own brand personality through virtual spokespersons, so what kind of design can stand out among the numerous images is a problem. This paper studies the influence of the characteristics of brand virtual spokespersons on the expression of brand personality. Firstly, the brand personality dimensions are classified as Ren, Zhi, Yong, Ya and Le and then the characteristics of virtual spokespersons are identified as likability, expertise and relevance. After that, the interaction between brand personality and virtual spokesman characteristics is confirmed, and the dimensions of the two are combined. Finally, some opinions on the design of virtual spokespersons are given.

\section{LITERATURE REVIEW}

\subsection{Virtual Spokesman and Meaning Transfer Model}

\subsubsection{The concept of virtual spokespersons}

Brand virtual spokesman is a cartoon image designed by enterprises to convey the brand personality, culture, values and other information to consumers and establish a good brand relationship [6]. Many scholars define virtual spokespersons as non-human roles for promoting products or brands [7], virtual spokespersons can convey the brand personality and culture according to the historical background and brand significance of the enterprise[8], and can be regarded as a part of the intangible assets of the enterprise [9].

\subsubsection{Meaning transfer model}

According to The Meaning Transfer Model, the internalization process of brand spokesperson to target consumer groups is the process of spokesperson image Transfer. This process mainly includes three stages: first, in a specific cultural context, the spokesman forms a unique representation, highlighting the value demands of certain social groups such as gender, age, personality, social status and lifestyle; Second, when an enterprise chooses a suitable spokesman according to its own brand connotation and target consumer group characteristics, the brand spokesman will transfer its own representational meaning and image to the brand. Third, consumers choose or consume this brand or product to obtain the representational meaning and reconstruct their self-image.

Therefore, experts proposed that in the process of image transfer, the unique and distinctive personality image of the spokesperson must match the brand personality of the spokesperson, otherwise it will have a negative impact on the advertising effect of the brand[10].

\subsubsection{The influence of the development of information technology on the design of virtual spokespersons}

The continuous development of technology provides a broad space for virtual spokesman. CG technology, 3D production, motion capture, holographic technology, 3D printing, various new technologies emerge one after another, and virtual characters can participate in people's lives in more and more ways. Based on these technologies, the created virtual characters can also be endowed with various humanized functions such as language function, game function, music function and communication function. At the same time, according to the needs of planners can be arbitrary transformation until consumer satisfaction. All these provide a new direction and possibility for the image design of virtual spokespersons, and enable people to develop from the traditional cartoon doll-like corporate virtual image to the comprehensive intelligent virtual idol.

\subsection{The Concept of Brand Personality, the Relationship between Brand Personality and Virtual Spokespersons}

\subsubsection{The concept of brand personality}

The soul of a brand is personality, which represents the difference between a brand and other brands. Nowadays, the academic circle is in favour of the view that "brand personality is an important component dimension of brand image" rather than the unique one[11]. Brand personality reflects consumers' perception of a brand and can provide symbolic and self-expression functions compared with product characteristics. Experts believe that brand personality refers to a group of human characteristics possessed by a brand. Human characteristics include personality traits, such as reliable, fashionable and successful. It also includes other demographic characteristics, such as gender, age, and social status. The brand personality opinions of Aaker and others are gradually recognized and respected by the outside world[12].

\subsubsection{The relationship between virtual spokespersons and brand personality}

As virtual spokespersons are designed for specific commercial purposes, they can not only show the product or corporate image, but also convey the brand personality and culture according to the historical background and brand significance of the enterprise in the early stage of design, which can be regarded as part of the intangible assets of the enterprise. Therefore, brand virtual spokesman 
is an important medium for brand to convey brand personality to consumers.

\subsection{Personality Characteristics of Virtual Spokespersons and Brand Personality Dimensions in China}

Existing research shows that the characteristics of the virtual spokesperson such as credibility, attractiveness, expertise, likability, trustworthiness and relevance will affect consumers' brand attitude and purchase intention[13] Chang modified the model proposed by Garretson and Niedrich in his research, and believed that consumers' perception of brand virtual spokesmen includes three characteristics, including likability, expertise and relevance. These three characteristics have also become important criteria for studying the personality of virtual spokespersons.[14]

Huang Shengbing, Lu Taihong in 2003 adopted the first western vocabulary method, factor analysis and the trait theory as the basis of methodology, from the Chinese language, Chinese brand for content, through the empirical study of Chinese consumers to develop brand personality dimensions and scale of China, got the China's five dimensions of brand personality and the characteristics of the uniqueness of Chinese brand personality dimensions[14]. And from the perspective of Chinese traditional culture explained the Chinese brand personality dimension. Specifically, Chinese brand personality has five dimensions -- "Ren, Zhi, Yong, Ya, Le". The establishment of Chinese brand personality dimension sets up consumers' perception of brand personality and provides a scale[15].

\section{Research Methods and Data}

\subsection{Measurement of Research Variables}

This study involves a total of 8 variables. Among them, the characteristics of brand virtual spokespersons include three variables: Likability, Expertise and Relevance. Brand personality characteristics include "Ren, Zhi, Yong, Ya, Le" five variables. The items in the questionnaire were determined on the basis of combing existing literature.

Chang[11] classified the characteristics of brand virtual spokespersons into likability, expertise and relevance. Among them, the measurement of the likability of the virtual spokespersons is mainly derived from the study of Mize and Kinney[12]. The expertise test items of virtual spokespersons are mainly derived from Ohanian[9], Garretson and Niedrich[7], Mize and Kinney[12]. The relevance of virtual spokespersons was derived from the study of Sengupta et al.[13], Garretson and Niedrich[7], with four items[16]. See Table 1 for details.
Table 1. The test item of brand virtual spokesman characteristics

\begin{tabular}{|c|c|c|}
\hline Variable & Test Item & Sources \\
\hline \multirow{4}{*}{$\begin{array}{l}\text { Likability } \\
\text { (SCL) }\end{array}$} & $\begin{array}{l}\text { I think the virtual } \\
\text { spokesperson looks very } \\
\text { cute. }\end{array}$ & \multirow{4}{*}{$\begin{array}{c}\text { Mize \& } \\
\text { Kinney (2008) }\end{array}$} \\
\hline & $\begin{array}{l}\text { I find spokesperson } \mathrm{x} \\
\text { very flattering. }\end{array}$ & \\
\hline & $\begin{array}{c}\text { I find spokesperson } \mathrm{x} \\
\text { delightful. }\end{array}$ & \\
\hline & $\begin{array}{l}\text { I find spokesperson } \mathrm{x} \text { is } \\
\text { humorous and } \\
\text { interesting. }\end{array}$ & \\
\hline \multirow{5}{*}{$\begin{array}{l}\text { Expertise } \\
(\mathrm{SCR})\end{array}$} & $\begin{array}{l}\text { I think spokesperson } \mathrm{x} \\
\text { looks like an expert. }\end{array}$ & \multirow{5}{*}{$\begin{array}{c}\text { Ohanian } \\
\text { (1991) } \\
\text { Garretson \& } \\
\text { Niedrich } \\
\text { (2004), } \\
\text { Mize \& } \\
\text { Kinney } \\
\text { (2008) }\end{array}$} \\
\hline & $\begin{array}{l}\text { I think spokesperson } \mathrm{x} \\
\text { looks experiences. }\end{array}$ & \\
\hline & $\begin{array}{l}\text { I think spokesperson } \mathrm{x} \\
\text { looks knowledgeable. }\end{array}$ & \\
\hline & $\begin{array}{l}\text { I think spokesperson } \mathrm{x} \\
\text { looks very capable. }\end{array}$ & \\
\hline & $\begin{array}{l}\text { I think spokesperson } \mathrm{x} \\
\text { looks very skilled. }\end{array}$ & \\
\hline \multirow{4}{*}{$\begin{array}{l}\text { Relevance } \\
\text { (SCE) }\end{array}$} & $\begin{array}{l}\text { It makes sense for } \mathrm{X} \text { to } \\
\text { endorse the products of } \\
\text { brand Y. }\end{array}$ & \multirow{4}{*}{$\begin{array}{l}\text { Sengupta et al. } \\
\text { (1997) } \\
\text { Garretson \& } \\
\text { Niedrich } \\
(2004)\end{array}$} \\
\hline & $\begin{array}{l}\text { It is appropriate for } \mathrm{X} \text { to } \\
\text { endorse the products of } \\
\text { brand } \mathrm{Y} \text {. }\end{array}$ & \\
\hline & $\begin{array}{c}\mathrm{X} \text { is related to the } \\
\text { products of brand } \mathrm{Y} \text {. }\end{array}$ & \\
\hline & $\begin{array}{l}\text { Generally, X matches the } \\
\text { products of brand Y. }\end{array}$ & \\
\hline \multicolumn{3}{|c|}{$\begin{array}{l}\text { Huang and Lu divide Chinese brand personality into five } \\
\text { dimensions: Ren, Zhi, Yong, Ya, Le[14]. The brand } \\
\text { personality scales are all from Huang and Lu. After the } \\
\text { revision of the pre-survey, there are } 32 \text { items in the five } \\
\text { dimensions: (1)Ren: placid, harmonious, benevolent, } \\
\text { domestic, sweet; (2)Zhi: professional, authoritative, } \\
\text { trustworthy, leadership, sedate, expert, mature, responsible, } \\
\text { rigorous, innovative, literate; (3)Yong: majestic, rugged, } \\
\text { strong, decisive, brave; (4)Ya: elegant, romantic, taste, } \\
\text { decent, style, charming; (5)Le: joyous, auspicious, } \\
\text { optimistic, confident. }\end{array}$} \\
\hline
\end{tabular}

\subsection{Data Processing and Results}

\subsubsection{Questionnaire design}

The purpose of this study is to measure the expression mechanism of the main characteristics of brand virtual spokespersons on brand personality. Since in daily life, not all consumers will pay attention to the brand virtual spokespersons. In order to ensure the validity of the 
questionnaire, we give the definition and examples of the brand virtual spokespersons at the beginning of the questionnaire, and explain the difference between the virtual spokespersons and the celebrity spokespersons.

Before the research subject, we set the question "can you recall a most impressive 'virtual brand spokesperson'? This question is used to screen subjects. If the subject chooses "cannot", the research will be finished. If the subject chooses "can", the name of the most impressive brand virtual spokesperson (" virtual spokesperson $\mathrm{x}$ "for short) and the brand represented by the virtual spokesperson (" brand $y^{\prime \prime}$ for short) should be written in the next open question. In the measurement of research variables of the research subject, virtual spokesperson $\mathrm{x}$ is taken as the object to measure the characteristics of the virtual spokesperson, that is, the likability, expertise and relevance of the virtual spokesperson, and brand personality of the brand represented by the virtual spokesperson is measured with brand $y$ as the object. Therefore, in order to ensure the corresponding relationship between the characteristics of virtual spokespersons and brand personality, if the virtual spokespersons $\mathrm{x}$ and brand $\mathrm{y}$ do not match, they will be excluded as invalid questionnaires.

The questionnaire is divided into four parts. The first part is the preface, which mainly introduces the content and purpose of the survey and differentiates the concept of virtual spokespersons. The second part is the screening part. The subjects who cannot recall the virtual spokespersons and their endorsement brands will be screened, and the matching relationship between virtual spokespersons and brands will be established. The third part is the research subject, including the evaluation of virtual spokespersons' likability, expertise and relevance, and the evaluation of brand personality. The fourth part is the statistical variables of personal characteristics, including gender and age.

Considering that Chinese people are influenced by the doctrine of the mean and tend to compromise, we finally chose the six-level scale to measure the items in the questionnaire. The six levels are: strongly agree, strongly agree, slightly agree, slightly disagree, slightly disagree, strongly disagree. In order to ensure the accuracy of this survey, a preliminary survey was conducted before the formal survey. The wording of the questionnaire, whether the test items were ambiguous, and whether the research variables could be effectively measured were tested and corrected. The average response time to the questionnaire was 335 seconds.

\subsubsection{Data collection and analysis}

The questionnaire survey was conducted on the website of "questionnaire star", and 87 valid questionnaires were received. Among them, there were 2 questionnaires that took less or more time to complete. 25 questionnaires for choosing "unable" to recall brand virtual spokespersons; As this survey is conducted online, the samples are well representative in terms of gender, age, education background, occupation and income.
Data analysis we used SPSS software for data analysis: since the test items used in this study were all from previous studies, the content validity could be guaranteed. In this study, Principal Components Analysis in Factor Analysis was used to test the construct validity. Before that, the results of KMO are used to confirm whether the data is suitable for factor analysis. The KMO values are shown in the table below, indicating that the data has good construct validity. (above 0.9 means very suitable; 0.8 means suitable; 0.7 is general; 0.6 means not suitable; Anything below 0.5 is highly inappropriate. The KMO statistic is between 0 and 1. When the KMO value is closer to 1 , it means that the correlation between variables is stronger, and the original variables are more suitable for factor analysis. When the sum of squares of simple correlation coefficients between all variables is close to 0 , the KMO value is close to 0 . The closer the KMO value is to 0 , the weaker the correlation between variables is, and the original becomes less suitable for factor analysis.)

Continue to use SPSS software to conduct linear regression for independent variables and dependent variables, and get the regression coefficient $(\beta)$ and correlation coefficient $(t)$ between the respective variables and dependent variables, as shown in the following table.

Table 2. The test item of brand virtual spokesman characteristics

\begin{tabular}{|l|c|c|c|}
\hline & Likability & Expertise & Relevance \\
\hline Ren & $0.143(1.062)$ & $0.288(2.304)$ & $0.189(1.394)$ \\
\hline Zhi & $0.092(0.867)$ & $0.648(6.591)$ & $0.099(0.922)$ \\
\hline Yong & $0.133(1.064)$ & $0.545(4.710)$ & $-0.060(-0.477)$ \\
\hline Ya & $0.085(0.834)$ & $0.667(7.058)$ & $0.120(1.164)$ \\
\hline Le & $0.325(2.485)$ & $-0.227(-1.872)$ & $0.310(1.564)$ \\
\hline KMO & 0.713 & 0.879 & 0.809 \\
\hline
\end{tabular}

\section{DISCUSSION AND SUGGESTION}

\subsection{The Relationship between Likability and Test Items}

According to the above data, the likability of virtual spokespersons has no significant relationship with the brand personality dimensions of benevolence, wisdom, courage and elegance. This study believes that the likability of virtual spokespersons mainly reflects the cuteness of the brand, namely the popularity, and is not related to the brand personality. Wisdom: composed, rigorous and other related; Nor does it have anything to do with the brand's personality as a kind of moral courage, such as bravery and decisiveness, and the brand's character as a personal image, such as strength and roughness. It also has nothing to do with elegant brand personality, that is, elegant words and deeds, romantic, ideal personality and beautiful, dignified features, or reflect the respect of others for their own. Data according to the above knowable virtual spokesperson likability and joy of the brand personality dimensions were 
positively significant relationship, therefore this study thinks that because of the sweet degree is the main performance of the brand of lovely the popular degree, the representative of humor in a virtual likability has the very important role, investigation and research, the subjects mentioned types include humor and lovely, happy, lively, uncoordinated, and human nature, etc. It is positively correlated with the brand personality dimension of joy, optimism, self-confidence and fashion.

\subsection{Relationship between Expertise and Test Items}

Based on the above data, it can be seen that the expertise of virtual spokespersons is significantly positively correlated with the dimensions of benevolence, wisdom, courage and elegance in their brand personality, and significantly negatively correlated with joy. Therefore, this study believes that specialization is a perception that information source is effective or has product knowledge. Information credibility is determined by the reliability (reliability) and expertise of the information source. The higher the expertise and reliability of the spokespersons, the better the advertising effect. The advertising effect represents the characteristics and personality of a brand. Therefore, the higher the expertise of the virtual spokespersons, the better the advertising effect, and the better the benevolence, wisdom, courage and elegance of the virtual spokespersons, which can make consumers feel that the brand has these attributes. But for this dimension is concerned, in the case of virtual spokesperson professional enhancement, due to the virtual spokesperson to express more specialized information, the representative of the virtual image is bound to more formal and serious, it will inhibit expression of properties, make consumers think the brand is serious, rather than a relaxed and happy.

\subsection{Relationship between Relevance and Test Items}

According to the above data shows the relevance of virtual spokesperson of the brand personality with benevolence, wisdom, brave, and no significant relationship between no dimension, therefore this study thinks, because relevance is virtual spokesperson its products in the promotion of suitable degree, it is the precondition of virtual spokesperson to express brand personality, but the relevance is stronger and cannot explain what virtual spokesperson expressed the attributes of the brand.

\subsection{Suggestions}

In the design of virtual spokesmen, in order to highlight the likability of virtual spokesmen, we can combine popular animation language to improve the cuteness of virtual spokesmen[17]. a) the virtual spokesman should have a complete character image. When personifying an object, it is no longer simple to add eyes, nose and limbs, but first to have a complete human shape, and then from the shape, color, temperament, personality and other aspects of the comprehensive consideration of design.

b) the modeling should conform to the aesthetic taste of young people, conform to the definition of idol appearance, personification of the role, or beautiful or lovely, no matter facial appearance or figure proportion contains an "ideal" aesthetic, or "aestheticism" aesthetic orientation.

c) in addition, the costume design of the characters is also relatively elegant. The character modeling is reflected in the details of the prototype, including the refinement and generalization of the modeling, the extraction and application of color, etc. So that the personification image in appearance and temperament can be effective to restore the object.

d) in the design of virtual spokesmen, some animation images that have appeared in the past can be selected[18], which can arouse the memories of consumers' childhood, arouse emotional resonance, and get twice the result with half the effort in the shaping of brand personality.

In the design of virtual spokespersons, in order to highlight the expertise of virtual spokespersons: when enterprise in the design of virtual spokesperson, but from the perspective of the character in dress, expressions, action and to carry on the design, such as Mr Michelin, Kang Shifu, Mr Contac, thus aeriform in professional image shaping brands, reduce target consumption group of brand product quality related concerns, to form a positive brand personality[19].

\section{CONCLUSION}

According to the above data, the expertise of virtual spokespersons has a significant impact on the Le dimension of brand personality, while expertise has a significant positive correlation with the Ren, Zhi, Yong, Ya dimensions of brand personality, and a significant negative correlation with the Le dimension. However, the relevance of virtual spokespersons cannot express brand personality. Therefore, when designing virtual spokespersons for enterprises in the future, when brand personality can be included in several dimensions, such as benevolence, wisdom, courage and joy, we can pay attention to the expertise of virtual spokespersons, making them knowledgeable and skilled in spokespersons' design. When the brand personality can be summarized by Le, we can pay attention to the cuteness of the virtual spokesmen and design the spokesmen to be cute and likable.

\section{REFERENCES}

[1] Aaker, J. Dimensions of Brand Personality. Journal of Marketing Research, 1997(34): 342-350. 
[2] Zhang, Y. Research on the influence of cuteness and nostalgia of virtual spokespersons on brand loyalty of consumers. Nanjing University of Science and Technology, Master's thesis. 2015.

[3] Zhang, N. Research on the influence of virtual spokespersons on brand assets: the mediating effect of brand experience and the mediating effect of consumers' personal characteristics and product characteristics. Wuhan University, Doctor's dissertation. 2013.

[4] Phillips, B.J. Defining Trade Characters and Their Role in American Popular Culture. The Journal of Popular Culture, 1996(29): 143-58.

[5] Folse, J., Netemeyer, R. D., and Burton, S. Spokescharacters: How the Personality Traits of Sincerity, Excitement and Competence Help to Build Equity. Journal of Advertising, 41(1), 17-32.2012.

[6] Callcott, M. F. \& Alvey, P.A. Toons Sell... and Sometimes They Don't: An Advertising Spokescharacter Typology and Exploratory Study. Proceedings of the 1991 Conference of the American Academy of Advertising, 1991, Inc, pp.43-52.

[7] Garretson, J.A. \& Niedrich, R.W. Spokes-characters: Creating Character Trust and Positive Brand Attitudes. Journal of Advertising, 2004, 33(2): 25-36.

[8] Callcott, M.F. \& Phillips, B.J. Elves make Good Cookies: Creating Likable Spokes- character

Advertising. Journal of Advertising Research, 1996, 36(4): 73-78.

[9] Ohanian, R. The Impact of Celebrity Spokespersons' Perceived Image on Consumers' Intention to Purchase. Journal of Advertising Research, 1991, 31(1): 46-54.

[10] Keller, K. L. Conceptualizing, Measuring, and Managing Customer-based Brand Equity. The Journal of Marketing, 1993, 57(1): 1-22.
[11] Chang, K. The Effectiveness of the SpokesCharacter in Creating Brand. Society for Marketing Advances Proceedings, 2008: 268-269.

[12] Mize,J. \& Kinney, L. Spokes-character Influence on Brand Relationship Quality Factors. American Academy of Advertising Conference Proceedings, 2008: 177-187

[13] Sengupta, J., Goodstein, R.C., Boninger, D.S. All Cues Are Not Created Equal: Obtaining Attitude Persistence under Low-Involvement Conditions. Journal of Consumer Research, 1997, 23(4): 351-361.

[14] Huang, S. \& Lu, T. The localization research of brand personality dimension. Journal of Nankai Management Review, 2003(1): 14-9. (In Chinese)

[15] Gao, J. Research on the design of brand virtual image spokesman - a case study of YY voice. Shanghai University, Master's thesis, 2015.

[16] Zhang, Q. The virtual design of brand spokesperson. Enterprise Reform and Management, 2015(1): 1-2. (In Chinese)

[17] Wang, Z. A study on the marketing and communication strategies of animation images in commercial advertisements - a case study of Toyota's "Doraemon" and "Hatsune Miku" advertising series. South-Central Minzu University, Master's thesis, 2013.

[18] Zheng, P. Research on the influence of the characteristics of brand virtual spokespersons on advertising effect - from the perspective of quasi-social interaction. Huaqiao University, Master's thesis, 2015.

[19] Wang, H. \& Ma, M. The credibility factor structure of celebrity advertising source. Journal of Psychology, 2004, 36(3): 10-15. (In Chinese) 